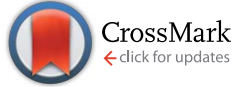

Cite this: J. Mater. Chem. A, 2016, 4, 869

Received 27th August 2015

Accepted 27th November 2015

DOI: $10.1039 / \mathrm{c} 5 \operatorname{ta} 06758 \mathrm{~h}$

www.rsc.org/MaterialsA

\section{Titanium oxynitride microspheres with the rock- salt structure for use as visible-light photocatalysts $\uparrow$}

\author{
Jung Bo Yoo, ${ }^{a}$ Hyo Jin Yoo, ${ }^{a}$ Hyuk Joon Jung, ${ }^{a}$ Han Sol Kim, ${ }^{a}$ Sora Bang, ${ }^{a}$

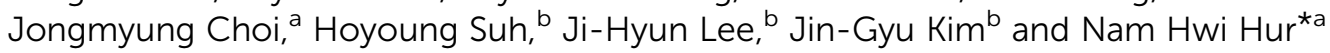

Novel photocatalysts $\left(\mathrm{TiO}_{2}\left(\mathrm{aTiO}_{1-x} \mathrm{~N}_{x}\right)\right.$ with the core-shell geometry were synthesized by controlled nitridation of $\mathrm{TiO}_{2}$ microspheres using ammonia gas. The oxynitride phases $\left(\mathrm{TiO}_{1-x} \mathrm{~N}_{x}\right)$ with a cubic rocksalt structure are exclusively formed on the surface of the $\mathrm{TiO}_{2}$ microspheres while the cores of the microspheres retain the $\mathrm{TiO}_{2}$ phase without nitrogen doping. Various spectroscopic data confirm the formation of the core-shell structure, denoted as $\mathrm{TiO}_{2}\left(\mathrm{aTiO}_{1-x} \mathrm{~N}_{x}\right.$. The $\mathrm{TiO}_{2}\left(\mathrm{aTiO}_{1-x} \mathrm{~N}_{x}\right.$ materials showed superior photocatalytic activities for the decomposition of methylene blue as well as the generation of photocurrent under visible-light. It is evident that the $\mathrm{TiO}_{1-x} \mathrm{~N}_{x}$ phase is the key element to induce the photocatalytic activity. Specifically, the partial doping of nitrogen into the TiO matrix is crucial for visiblelight absorption.

\section{Introduction}

Titanium dioxide $\left(\mathrm{TiO}_{2}\right)$ has been extensively studied because of its wide applications in solar-driven environmental and energy technologies since Honda and Fujishima discovered water splitting on a $\mathrm{TiO}_{2}$ electrode under UV light. ${ }^{1} \mathrm{TiO}_{2}$ has several merits as a photocatalyst including large abundance, low toxicity, and excellent stability. ${ }^{2,3}$ However, a major drawback is that it absorbs only UV light due to its large band gap energy (3.0 and $3.2 \mathrm{eV}$ for the rutile and anatase phases, respectively). ${ }^{4,5} \mathrm{~A}$ wide range of approaches have been explored to narrow the band gap of $\mathrm{TiO}_{2}$. Chen et al. reported that disordered $\mathrm{TiO}_{2}$ nanoparticles (NPs) prepared by the hydrogenation method exhibit significantly enhanced activity in the production of hydrogen $\left(\mathrm{H}_{2}\right)$ from water under visible-light. ${ }^{6}$ The chemical composition of $\mathrm{TiO}_{2}$ was also modified by doping nonmetal atoms such as carbon $(\mathrm{C})$, hydrogen $(\mathrm{H})$, nitrogen $(\mathrm{N})$, fluorine $(\mathrm{F})$, and sulfur (S) into the oxygen (O) site..$^{7-13}$ The dopants typically generate impurity states above the valence band of $\mathrm{TiO}_{2}$, which results in the upshift of the valence band edge and the improvement in the solar absorption efficiencies of $\mathrm{TiO}_{2}$. In particular, N-doped $\mathrm{TiO}_{2}$ (nominally $\mathrm{TiO}_{2-x} \mathrm{~N}_{x}$ ) materials with low $\mathrm{N}$ content $(\sim 1 \mathrm{wt} \%)$ have been thoroughly studied..$^{10,14}$ They are typically prepared by annealing $\mathrm{TiO}_{2}$ at temperatures below

aDepartment of Chemistry, Sogang University, Seoul 121-742, Korea. E-mail: nhhur@ sogang. ac. kr

${ }^{b}$ Nano-Bio Electron Microscopy Research Group, Korea Basic Science Institute, Daejeon 34133, Korea

$\dagger$ Electronic supplementary information (ESI) available. See DOI: $10.1039 / \mathrm{c} 5$ ta06758h
$600{ }^{\circ} \mathrm{C}$ under an ammonia $\left(\mathrm{NH}_{3}\right)$ atmosphere, which exhibit excellent catalytic activities in the visible light range. But their absorption is not fully covered in the solar spectrum. Moreover, $\mathrm{TiO}_{2-x} \mathrm{~N}_{x}$ is unstable after going through the photocatalytic reaction and easily returns to parent $\mathrm{TiO}_{2}$.

Despite the extensive interest in $\mathrm{N}$-doping in the $\mathrm{TiO}_{2}$ matrix, there are few studies on $\mathrm{N}$-doped titanium monoxide (TiO) materials with a cubic rock-salt structure due to the difficulty to control the doping level and the metallic character of TiO..$^{15,16}$ Simon et al. reported the synthesis of N-doped TiO NPs using laser pyrolysis, which shows a large shift of the absorption threshold in the visible region. ${ }^{17}$ Similar to TiO, titanium nitride (TiN) also adopts a cubic rock-salt structure and is considered to be metallic. In contrast to bulk TiN materials, TiN films prepared by using a cathodic arc technique have a band gap of about $2.0 \mathrm{eV}$, indicating that TiN can be semiconducting if the particle size reduces to the nanometer scale..$^{18}$ Very recently, Zheng et al. prepared $\mathrm{TiO}_{x} \mathrm{~N}_{y} @ \mathrm{TiN}$ composites through the flash oxidation of commercial TiN particles, demonstrating a high photocatalytic activity for $\mathrm{H}_{2}$ production under visible light irradiation. ${ }^{19}$ However, the non-equilibrium quick oxidation of TiN particles in the presence of 2,4,6-trinitrophenol hampers the control of the optimal doping level.

Here we report a convenient and reproducible method to make a new visible-light active composite photocatalyst. Controlled nitridation of monodisperse $\mathrm{TiO}_{2}$ microspheres, accomplished by flowing ammonia gas, converted the shell into the $\mathrm{TiO}_{1-x} \mathrm{~N}_{x}$ phase and transformed the core into the amorphous $\mathrm{TiO}_{2}$ phase. As a result, the nitrided product has the core-shell type structure, which is composed of two phases: a crystalline $\mathrm{TiO}_{1-x} \mathrm{~N}_{x}$ phase as the shell and an amorphous 
$\mathrm{TiO}_{2}$ phase as the core. Hereafter, we denote it as $\mathrm{TiO}_{2} @$ $\mathrm{TiO}_{1-x} \mathrm{~N}_{x}$. The $\mathrm{TiO}_{2}$ @TiO ${ }_{1-x} \mathrm{~N}_{x}$ material exhibited excellent photocatalytic activities under visible-light, including the degradation of methylene blue and the production of photocurrent. The nitrogen doping in $\mathrm{TiO}_{1-x} \mathrm{~N}_{x}$ is considered to be responsible for absorbing visible light.

\section{Experimental section}

\section{Chemicals}

All chemicals were purchased from commercial suppliers and were used without further purification unless otherwise stated. Ethanol, dodecyl amine (98\%, DDA), methylene blue (MB), terephthalic acid (98\%), sulfuric acid (>95\%), and Nafion were purchased from Sigma-Aldrich (St Louis, USA). Titanium tetraisopropoxide (TTIP) were obtained from Tokyo Chemical Industry (Tokyo, Japan).

\section{Synthesis of monodisperse $\mathrm{TiO}_{2}$ microspheres}

Monodisperse $\mathrm{TiO}_{2}$ microspheres were prepared using TTIP as the titanium source. In brief, $3 \mathrm{~mL}$ of DDA, $4 \mathrm{~mL}$ of deionized water, and $300 \mathrm{~mL}$ of ethanol were added to a round-bottom flask, and the solution was cooled to $-20{ }^{\circ} \mathrm{C}$ and stirred for $1 \mathrm{~h}$. Using a syringe, a solution containing $6 \mathrm{~mL}$ of TTIP and $8 \mathrm{~mL}$ of ethanol was injected into the cold solution. After vigorous stirring for $20 \mathrm{~h}$ at $-20{ }^{\circ} \mathrm{C}$, white precipitates that formed gradually were separated from the solution by centrifugation. The precipitates were sintered in air at $500{ }^{\circ} \mathrm{C}$ for $6 \mathrm{~h}$, yielding $1.44 \mathrm{~g}$ of $\mathrm{TiO}_{2}$ powders (89.2\% yield based on TTIP). The powders are composed of evenly dispersed spherical microspheres and their average diameter is approximately $560 \mathrm{~nm}$.

\section{Synthesis of $\mathrm{TiO}_{2} @ \mathrm{TiO}_{1-x} \mathbf{N}_{x}$ microspheres}

The $\mathrm{TiO}_{2}$ microspheres were annealed in $\mathrm{NH}_{3}$ at $700{ }^{\circ} \mathrm{C}$ to yield the desired $\mathrm{TiO}_{2} @ \mathrm{TiO}_{1-x} \mathrm{~N}_{x}$ microspheres. The flow of ammonia gas was controlled using a mass flow controller. The flow rate is fixed at 300 standard cubic centimeters per minute. Six different samples were prepared by controlling the annealing time. The annealing was performed at $700{ }^{\circ} \mathrm{C}$ for $1,4,7,10$, 24 , and $48 \mathrm{~h}$. The white microspheres gradually became blue when the sample was annealed under the ammonia atmosphere.

\section{Characterization}

Powder X-ray diffraction (XRD) data were collected using a Rigaku DMAX 2500 diffractometer ( $\mathrm{Cu} \mathrm{K} \alpha$; Rigaku, Japan) operating at $40 \mathrm{kV}$ and $150 \mathrm{~mA}$. High resolution transmission electron microscopy (TEM) was performed using a JEOL JEM2100F microscope (JEOL, Japan). Specimens for the TEM examinations were prepared by dispersing finely ground powders of the samples in anhydrous ethanol and then allowing a drop of the suspension to evaporate on a 400 mesh carboncoated grid. High resolution scanning electron microscopy (SEM) analyses were carried out using a Hitachi S-5500 microscope (Hitachi, Tokyo, Japan). Samples for the SEM analyses were prepared by dropping diluted samples in anhydrous ethanol on a lacey support grid. The samples were also subjected to chemical microanalyses using an Oxford Instruments INCA TEM 300 system (Oxford Instruments, Abingdon, UK) for energy dispersive X-ray (EDX) analysis. UV-visible absorption spectra of methylene blue (MB) solutions were recorded using a Perkin Elmer Lambda 950 spectrometer. The UV-visible absorption spectra of the powders were measured using an integrating sphere accessory by the diffuse reflectance method. Raman spectra were obtained at $25{ }^{\circ} \mathrm{C}$ using a LabRam HR Raman spectrometer (Horiba Jobin-Yvon) equipped with a liquid-nitrogen-cooled CCD multichannel detector. A $514 \mathrm{~nm}$ Ar-ion laser was used as the excitation source. Photoluminescence spectra were measured on a Hitachi F-7000 fluorescence spectrophotometer. Thermal gravimetric analysis was carried out using a TGA 2050 instrument (TA Instruments). The sample was placed on a platinum pan for each run. The data were collected in air from $25{ }^{\circ} \mathrm{C}$ to $700{ }^{\circ} \mathrm{C}$ at a rate of $5{ }^{\circ} \mathrm{C}$ $\min ^{-1}$. Adsorption and desorption measurements were carried out at $77 \mathrm{~K}$ using an ASAP 2420 instrument (Micromeritics, USA) with nitrogen as the adsorptive gas. The Brunauer-EmmettTeller (BET) surface areas were calculated using $P / P_{0}=0.05-0.3$ from the adsorption curve using the BET equation. The poresize distributions were obtained from the desorption curve using the density functional theory method. Prior to each sorption measurement, the sample was out-gassed at $300{ }^{\circ} \mathrm{C}$ for $24 \mathrm{~h}$ in vacuo to completely remove the impurities. To investigate the elemental compositions, X-ray photoelectron spectroscopy (XPS; Theta probe AR-XPS System, Thermo Fisher Scientific, UK) analysis using a mono-chromated Al K $\alpha$ X-ray source $(h \nu=1486.6 \mathrm{eV})$ was performed at the Korea Basic Science Institute (KBSI) in Busan. The nitrogen contents of the $\mathrm{TiO}_{2} @ \mathrm{TiO}_{1-x} \mathrm{~N}_{x}$ samples were analyzed using inductively coupled plasma atomic emission spectroscopy (ICP-AES, JY Ultima2C) at KBSI in Seoul.

\section{Results and discussion}

Monodisperse titanium oxynitride $\left(\mathrm{TiO}_{2} @ \mathrm{TiO}_{1-x} \mathrm{~N}_{x}\right)$ microspheres were prepared via two main pathways: (1) sol-gel synthesis of $\mathrm{TiO}_{2}$ microspheres and (2) nitridation of the $\mathrm{TiO}_{2}$ microspheres in $\mathrm{NH}_{3}$. Uniform $\mathrm{TiO}_{2}$ microspheres were prepared with solutions of TTIP, DDA, deionized water, and ethanol. The solution temperature was maintained at $-20{ }^{\circ} \mathrm{C}$ during the sol-gel polymerization process to make $\mathrm{TiO}_{2}$ microspheres with virtually identical diameters as well as to prevent agglomeration. After separating white precipitates from the solution, white precipitates were then heated at $500{ }^{\circ} \mathrm{C}$ for 6 $\mathrm{h}$, yielding white crystalline $\mathrm{TiO}_{2}$ microspheres with an average diameter of $560 \mathrm{~nm}$. The $\mathrm{TiO}_{2}$ microspheres were then nitrided at $700{ }^{\circ} \mathrm{C}$ in an $\mathrm{NH}_{3}$ atmosphere for different periods of time. The white $\mathrm{TiO}_{2}$ microspheres turned blue to deep blue, depending on the annealing time. This color change implies the formation of the rock-salt $\mathrm{TiN}_{1-x} \mathrm{O}_{x}$ phase in the $\mathrm{TiO}_{2}$ microsphere.

As illustrated in Fig. 1, the TEM and SEM images of representative $\mathrm{TiO}_{2} @ \mathrm{TiO}_{1-x} \mathrm{~N}_{x}$ microspheres clearly reveal that the size of parent $\mathrm{TiO}_{2}$ microspheres has noticeably shrunk but the 


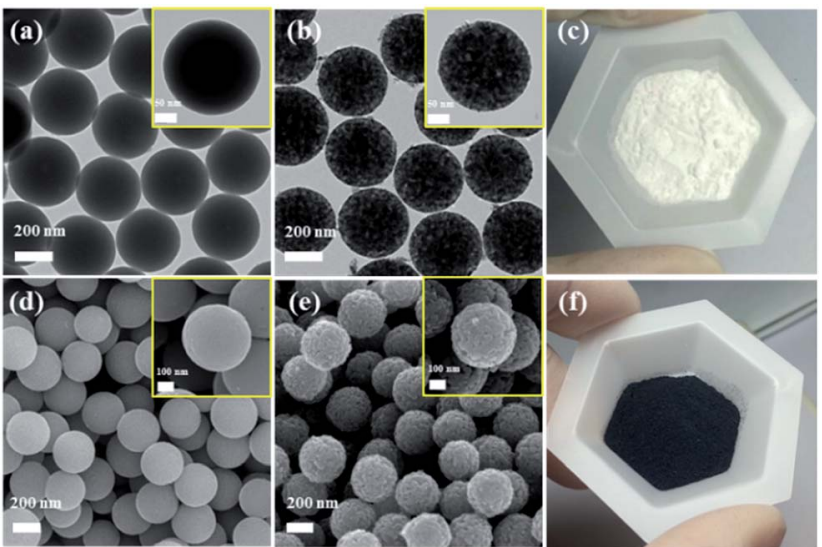

Fig. 1 TEM images of (a) parent $\mathrm{TiO}_{2}$ and (b) nitrided $\mathrm{TiO}_{2}\left(\mathrm{aTiO}_{1-x} \mathrm{~N}_{x}\right.$ microspheres where nitridation was done at $700{ }^{\circ} \mathrm{C}$ for $24 \mathrm{~h}$. Corresponding SEM images of (d) $\mathrm{TiO}_{2}$ and (e) $\mathrm{TiO}_{2}\left(\mathrm{aTiO}_{1-x} \mathrm{~N}_{x}\right.$ microspheres. Photos comparing (c) white $\mathrm{TiO}_{2}$ powders and (f) dark blue $\mathrm{TiO}_{2} \mathrm{a}$ $\mathrm{TiO}_{1-x} \mathrm{~N}_{x}$ samples are given in the right panel.

spherical shape appears to be remained. The results implicate that the annealing is effective mostly on the surface of the $\mathrm{TiO}_{2}$ microspheres at $700{ }^{\circ} \mathrm{C}$. The average diameter of $\mathrm{TiO}_{2} @$ $\mathrm{TiO}_{1-x} \mathrm{~N}_{x}$ microspheres nitrided for $24 \mathrm{~h}$ was reduced to about $420 \mathrm{~nm}$, which was estimated from the TEM images of $\mathrm{TiO}_{2} @ \mathrm{TiO}_{1-x} \mathrm{~N}_{x}$ in Fig. 1. However, the spherical shape has almost collapsed when the sample was nitrided for $24 \mathrm{~h}$ at 900 ${ }^{\circ} \mathrm{C}$ (Fig. S1 $\dagger$ ), indicating that annealing at high temperatures completely converts the oxide phase into the nitride phase.

We first investigated the structures of the $\mathrm{TiO}_{2} @ \mathrm{TiO}_{1-x} \mathrm{~N}_{x}$ microspheres with powder X-ray diffraction (XRD). The XRD data, given in Fig. 2, show that the anatase $\mathrm{TiO}_{2}$ phase is gradually transformed into $\mathrm{TiN}_{1-x} \mathrm{O}_{x}$ with a cubic rock-salt structure as the nitridation time increases. The sample nitrided at $700{ }^{\circ} \mathrm{C}$ for $4 \mathrm{~h}$ shows that two new XRD peaks at about $37.2^{\circ}$ and $43.2^{\circ}$, which can be assigned to (111) and (200) reflections

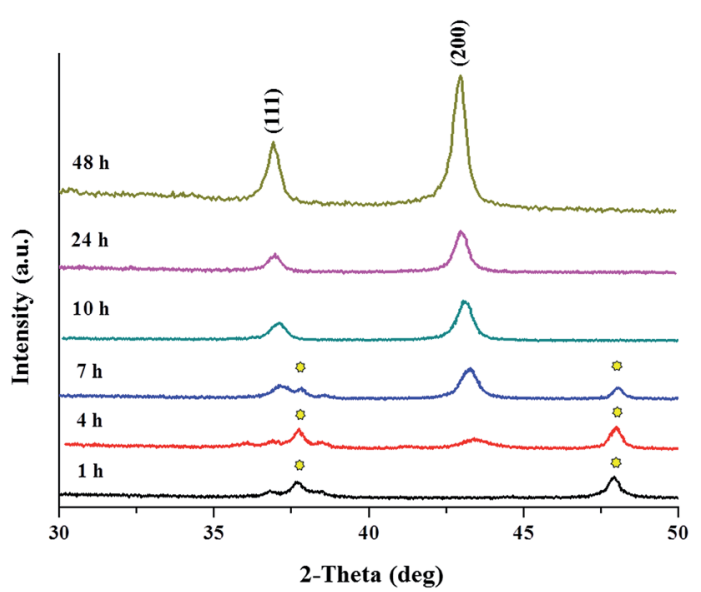

Fig. 2 Powder XRD patterns of $\mathrm{TiO}_{2} \mathrm{aTiO}_{1-x} \mathrm{~N}_{x}$ microspheres with different nitridation times. Two peaks were indexed on the basis of the JCPDS data. Peaks marked with an asterisk correspond to the $\mathrm{TiO}_{2}$ peaks. in $\mathrm{TiO}_{1-x} \mathrm{~N}_{x}$, appear along with the $\mathrm{TiO}_{2}$ peaks. ${ }^{20,21}$ This indicates that the anatase $\mathrm{TiO}_{2}$ phase coexisted with the cubic $\mathrm{TiO}_{1-x} \mathrm{~N}_{x}$ phase for a short period of time. When the nitridation was prolonged to $10 \mathrm{~h}$, the two peaks corresponding to cubic $\mathrm{TiO}_{1-x} \mathrm{~N}_{x}$ became more distinctive in the XRD data while other peaks from the anatase $\mathrm{TiO}_{2}$ phase almost completely disappeared. This suggests that the cubic $\mathrm{TiO}_{1-x} \mathrm{~N}_{x}$ phase is predominantly formed on the surface of the $\mathrm{TiO}_{2}$ microspheres nitrided for longer than $10 \mathrm{~h}$. The average crystallite size of $\mathrm{TiO}_{1-x} \mathrm{~N}_{x}$ synthesized by nitriding the $\mathrm{TiO}_{2}$ sample for $24 \mathrm{~h}$, determined from half-peak widths of the XRD peaks by applying the Scherrer equation, is $17.1 \mathrm{~nm}$. Lattice parameters were calculated using the (111) and (200) reflections in the XRD data. Table $\mathrm{S} 1 \dagger$ lists the calculated lattice parameters for $\mathrm{TiO}_{1-x} \mathrm{~N}_{x}$, along with the TiN and TiO standard data from the JCPDS file. Lattice constants of $\mathrm{TiO}_{1-x} \mathrm{~N}_{x}$ nitrided for $24 \mathrm{~h}$ are approximately in the middle of those for TiN and TiO, indicating that both $\mathrm{O}$ and $\mathrm{N}$ atoms are randomly disordered in the anion sites of the rock salt structure.

It is worth mentioning that the metallic TiN phase can be obtained only when the nitridation temperature was higher than $900{ }^{\circ} \mathrm{C}$. This suggests that the nitridation at $700{ }^{\circ} \mathrm{C}$ results in a partial replacement of oxygen in $\mathrm{TiO}_{2}$ with nitrogen rather than complete substitution. In the course of nitridation, $\mathrm{TiO}_{2}$ is the only oxygen source. It is thus conceivable that anion exchange between nitrogen and oxygen occurs initially at the surface of $\mathrm{TiO}_{2}$. Hence, the $\mathrm{TiO}_{2}$ microspheres annealed at 700 ${ }^{\circ} \mathrm{C}$ are composed of partially nitrided $\mathrm{TiO}_{1-x} \mathrm{~N}_{x}$ and unreacted $\mathrm{TiO}_{2}$ phases. Presumably the nitrided phase starts forming on the outer surface of a $\mathrm{TiO}_{2}$ microsphere and gradually penetrates into the inner core via the oxygen exchange. As a result, the outer shell is predominantly composed of $\mathrm{TiO}_{1-x} \mathrm{~N}_{x}$ whereas the inner core mainly consists of $\mathrm{TiO}_{2}$, yielding the core/shell type microspheres. The XRD data suggest that the nitridation time and temperature strongly influence the formation of $\mathrm{TiO}_{1-x} \mathrm{~N}_{x}$ at the surface and the shell thickness. It is interesting to note that any XRD peaks corresponding to the $\mathrm{TiO}_{2}$ phase were not displayed in the samples nitrided for 24 and $48 \mathrm{~h}$ although the unreacted $\mathrm{TiO}_{2}$ phase remains in the nitrided samples. The absence of the XRD peaks suggests that $\mathrm{TiO}_{2}$ in the core part might exist as an amorphous state. Nitridation appears to induce the disordered state via the exchange between oxygen and nitrogen in the boundary, which results in the transformation of the crystalline $\mathrm{TiO}_{2}$ phase into an amorphous $\mathrm{TiO}_{2}$ state. ${ }^{6,22}$ Another plausible cause is that X-ray might not penetrate enough into the inner core of the $\mathrm{TiO}_{2}$ microsphere. The diffracted peaks are thus ascribed mainly to the $\mathrm{TiO}_{1-x} \mathrm{~N}_{x}$ phase on the surface.

Raman spectroscopy was employed to confirm the structural changes by the nitridation time (Fig. 3). The anatase phase of $\mathrm{TiO}_{2}$ has six Raman-active vibrational modes including one $\mathrm{A}_{1 \mathrm{~g}}$ mode at $527 \mathrm{~cm}^{-1}$, two $\mathrm{B}_{1 \mathrm{~g}}$ modes at 382 and $504 \mathrm{~cm}^{-1}$, and three $\mathrm{E}_{\mathrm{g}}$ modes at 141,154 , and $654 \mathrm{~cm}^{-1} \cdot{ }^{23}$ The samples nitrided at $700{ }^{\circ} \mathrm{C}$ for $7 \mathrm{~h}$ showed virtually identical Raman patterns owing to the anatase $\mathrm{TiO}_{2}$ phase, suggesting that the conversion of $\mathrm{TiO}_{2}$ into $\mathrm{TiO}_{1-x} \mathrm{~N}_{x}$ is not complete at this stage. However, the $\mathrm{E}_{\mathrm{g}}$ mode at $154 \mathrm{~cm}^{-1}$ in the spectrum of the 


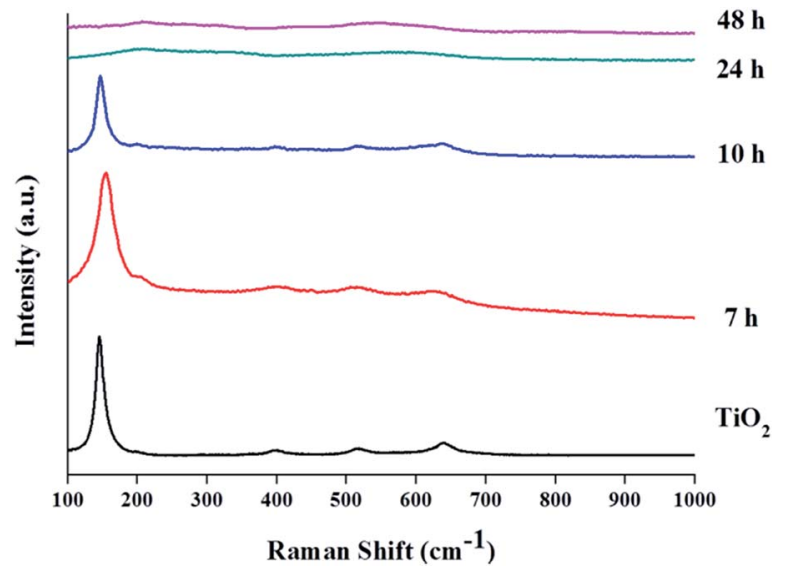

Fig. 3 Raman spectra of $\mathrm{TiO}_{2} \mathrm{aTiO}_{1-x} \mathrm{~N}_{x}$ microspheres with different nitridation times. For comparison, the Raman spectrum of $\mathrm{TiO}_{2}$ microspheres is displayed at the bottom.

sample nitrided for $10 \mathrm{~h}$ was significantly blue-shifted and noticeably broadened relative to that in the $\mathrm{TiO}_{2}$ spectrum, indicating that particle sizes were changed and defects were produced by nitridation. The Raman spectrum of the $\mathrm{TiO}_{2}$ microspheres nitrided for $24 \mathrm{~h}$ did not show any peaks corresponding to the anatase $\mathrm{TiO}_{2}$ phase and exhibited very broad peaks at $\sim 210, \sim 290$, and $\sim 570 \mathrm{~cm}^{-1}$ due to the cubic $\mathrm{TiO}_{1-x} \mathrm{~N}_{x}$ phase. The first-order Raman scattering is forbidden for the crystal with a cubic rock salt structure (space group: $F m 3 m$ ) because every atom is located at a site of inversion symmetry. ${ }^{24}$ Since $\mathrm{TiO}_{1-x} \mathrm{~N}_{x}$ contains a wide range of vacancies and defects, however, the forbidden rule can be relaxed and Raman peaks can thus be observed. ${ }^{25,26}$ The very broad peaks are probably associated with acoustic and optical modes of $\mathrm{TiO}_{1-x} \mathrm{~N}_{x}$. It is worth mentioning that the unreacted $\mathrm{TiO}_{2}$ phase was not detected in the $24 \mathrm{~h}$ sample by Raman analysis. This indicates that structural changes occur after nitridation, resulting in oxygen disorders primarily in the $\mathrm{TiO}_{2}$ phase in the core. The Raman data obtained from the nitrided samples are consistent with the XRD results.

The XRD and Raman results discussed above show the formation of the cubic $\mathrm{TiO}_{1-x} \mathrm{~N}_{x}$ phase but do not provide any direct evidence on the presence of the unreacted $\mathrm{TiO}_{2}$ phase. XPS data of the nitrided samples prepared by annealing at different dwell times were examined to assess the chemical environments and oxidation states of $\mathrm{Ti}$ and $\mathrm{N}$. In particular, two important regions including $\mathrm{Ti} 2 \mathrm{p}$ and $\mathrm{N} 1 \mathrm{~s}$ were carefully investigated for each sample. Fig. 4 shows the XPS spectra in the Ti 2p region (452-462 eV) of the $\mathrm{TiO}_{2} @ \mathrm{TiO}_{1-x} \mathrm{~N}_{x}$ samples. The Ti 2p XPS spectra of the $\mathrm{TiO}_{2}$ and nitrided samples exhibit drastic differences. The XPS data show that the binding energy was shifted from higher to lower values with increased annealing time. The sharp peak at $458.3 \mathrm{eV}$ is typical for the Ti $2 \mathrm{p}_{3 / 2}$ in anatase $\mathrm{TiO}_{2}$, namely the $\mathrm{Ti}^{4+}$ species. ${ }^{27,28}$ A notable feature is that the peak at $458.3 \mathrm{eV}$ is observed regardless of the annealing time, suggesting that the unreacted $\mathrm{TiO}_{2}$ phase is present even if the sample was nitrided for over $24 \mathrm{~h}$. The

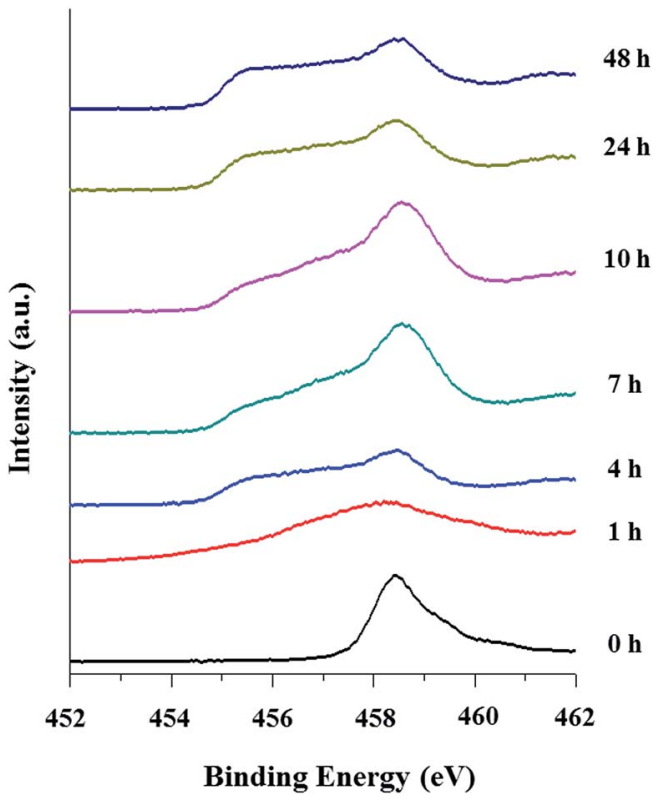

Fig. 4 Ti 2p XPS spectra of the $\mathrm{TiO}_{2} \mathrm{aTiO}_{1-x} \mathrm{~N}_{x}$ samples with different nitridation times.

broader peaks in the range of 455 to $458 \mathrm{eV}$ can be attributed to $\mathrm{Ti}^{2+}, \mathrm{Ti}^{3+}$, and $\mathrm{Ti}^{4+}$ species. ${ }^{29,30}$

For the sample nitrided for $24 \mathrm{~h}$, the spectral curve was fitted with five peaks centered at 455.6, 457.2, 458.3, 461.4, and 464.0 $\mathrm{eV}$, which is given in Fig. 5 . The Ti $2 \mathrm{p}_{3 / 2}$ XPS peaks are typically observed in the range of 455 to $460 \mathrm{eV}$. The lowest peak at 455.6 $\mathrm{eV}$ is ascribed to the $\mathrm{Ti}^{2+}$ species that could be associated with TiO. A peak centered at $457.2 \mathrm{eV}$ can be assigned to the $\mathrm{Ti}^{3+}$ of TiN or N-Ti-O bonding in $\mathrm{TiO}_{1-x} \mathrm{~N}_{x}{ }^{31}$ The peak at $458.3 \mathrm{eV}$ correlates with the $\mathrm{Ti}^{4+}$ in $\mathrm{TiO}_{2}$. Two peaks at 461.4 and $464.0 \mathrm{eV}$ are due to the Ti $2 \mathrm{p}_{1 / 2}$ spectra. One peak at $464.0 \mathrm{eV}$ is ascribed to the $\mathrm{Ti}^{4+}$ of $\mathrm{TiO}_{2}$ while the other at $461.4 \mathrm{eV}$ is associated with the $\mathrm{N}-\mathrm{Ti}-\mathrm{O}$ bonding in the oxynitride phase such as $\mathrm{TiO}_{1-x} \mathrm{~N}_{x}$. The Ti 2p XPS spectra suggest that the nitrided sample contains

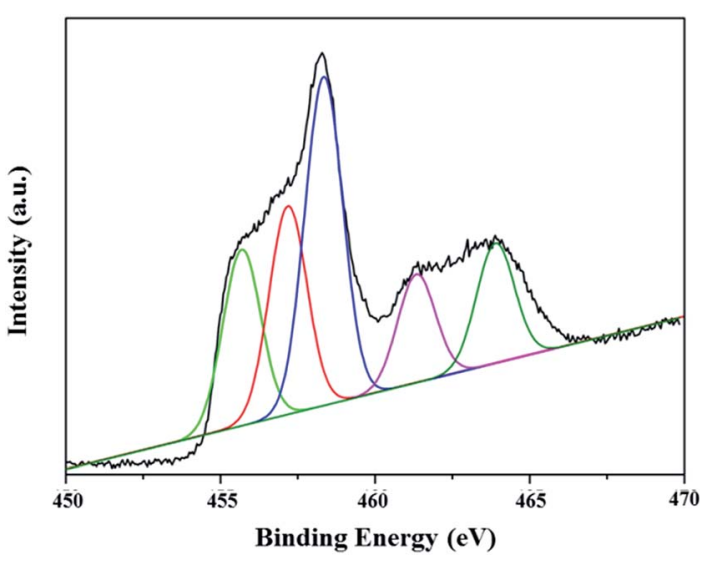

Fig. 5 Ti $2 p$ XPS spectra of $\mathrm{TiO}_{2}\left(\mathrm{aTiO}_{1-x} \mathrm{~N}_{x}\right.$ which was prepared by nitriding for $24 \mathrm{~h}$. The black line is an experimental XPS curve. The colored curves are the fittings of experimental XPS data, which can be decomposed into a superposition of five peaks shown as colored curves. 
the multiple oxidation states of $\mathrm{Ti}$ and might be composed of TiO, $\mathrm{TiO}_{1-x} \mathrm{~N}_{x}$, and $\mathrm{TiO}_{2}$.

The presence of $\mathrm{N}$ in the nitrided sample was clearly evidenced by the N 1s XPS spectra of $\mathrm{TiO}_{2} @ \mathrm{TiO}_{1-x} \mathrm{~N}_{x}$ as shown in Fig. 6. The $\mathrm{N}$ 1s peaks are more distinctive with increasing nitridation time. For the sample nitrided for $7 \mathrm{~h}$, a nearly single peak is observed. However, the samples with a longer nitridation time showed a broad peak. The inset in Fig. 6 is the $N$ 1s XPS spectrum of the $24 \mathrm{~h}$ sample. The red curve is the fitting data of experimental XPS data, which can be resolved into two peaks shown as blue curves. The first peak at $396.5 \mathrm{eV}$ is characteristic of the $\mathrm{N}$ dopant which corresponds to the $\mathrm{Ti}-\mathrm{N}$ bonding and the second one at $398.7 \mathrm{eV}$ can be attributed to the $\mathrm{N}-\mathrm{Ti}-\mathrm{O}$ species. ${ }^{32}$

From the XRD, Raman, and XPS data, it is conceivable that the nitrided samples are composed of $\mathrm{TiO}_{1-x} \mathrm{~N}_{x}$ and $\mathrm{TiO}_{2}$. However, it is very difficult to determine how much $\mathrm{TiO}_{2}$ phase in the parent $\mathrm{TiO}_{2}$ microsphere remains intact during the nitridation procedure. Thus, TGA was employed to determine the nitrogen content, which is useful to estimate the approximate ratio of $\mathrm{TiO}_{1-x} \mathrm{~N}_{x}$ to $\mathrm{TiO}_{2}$ in $\mathrm{TiO}_{2} @ \mathrm{TiO}_{1-x} \mathrm{~N}_{x}$. The TGA data of the nitrided samples were collected in air as a function of temperature. For comparative purposes, commercial TiN powder was also measured under the same conditions. All the samples were transformed into the rutile $\mathrm{TiO}_{2}$ phase after measurements, which were confirmed by XRD.

As illustrated in Fig. 7, the weight percentage of TiN increases to about $129 \%$, which is close to the theoretical value for the conversion of $\mathrm{TiN}$ into $\mathrm{TiO}_{2}$. In contrast, the weight gain of the sample nitrided at $700{ }^{\circ} \mathrm{C}$ for $24 \mathrm{~h}$ is about $115 \%$, which is much lower than that of TiN. This clearly suggests that the unreacted $\mathrm{TiO}_{2}$ phase remains in the nitrided samples. A notable feature is that the weight gains of the samples annealed for 24 and $48 \mathrm{~h}$ are not significantly different, supporting that the temperature annealed at $700{ }^{\circ} \mathrm{C}$ is not sufficient to completely convert $\mathrm{TiO}_{2}$ into $\mathrm{TiN}$.

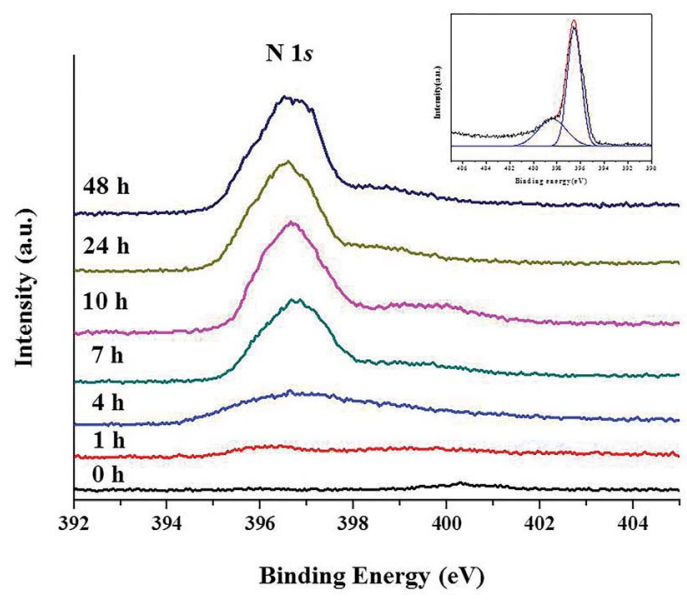

Fig. $6 \mathrm{~N}$ 1s XPS spectra of the $\mathrm{TiO}_{2}\left(\mathrm{aTiO}_{1-x} \mathrm{~N}_{x}\right.$ samples with different nitridation times. The inset is the fitting of experimental XPS data for the $24 \mathrm{~h}$ nitridation sample, which can be decomposed into a superposition of two peaks shown as blue curves. The black curve represents XPS data.

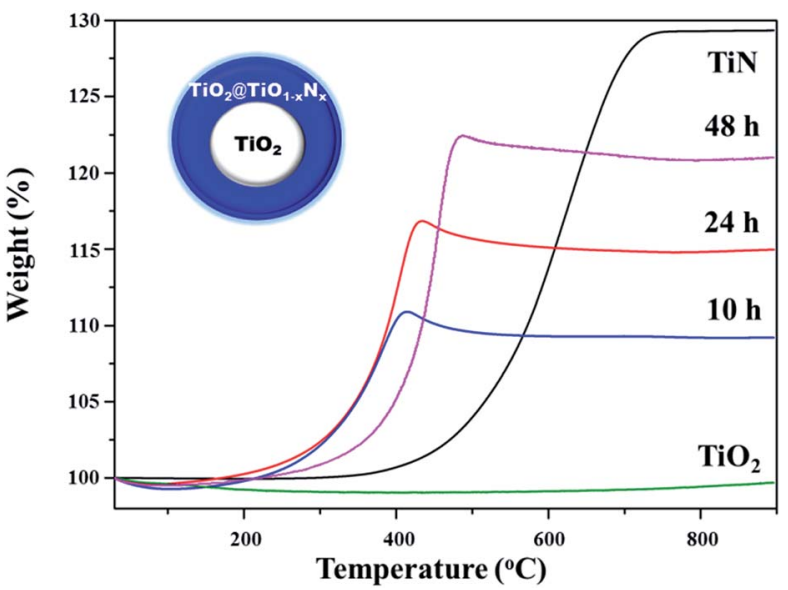

Fig. 7 Thermogravimetric analysis (TGA) data for the samples nitrided at $700^{\circ} \mathrm{C}$ for 10 and $24 \mathrm{~h}$. Data were collected in air at a heating rate of $10{ }^{\circ} \mathrm{C}$ per minute. For comparison, TGA data for TiN were included. The inset is a simplified drawing of $a \mathrm{TiO}_{2} @ \mathrm{TTiO}_{1-x} \mathrm{~N}_{x}$ microsphere with a shell thickness of about $56 \mathrm{~nm}$ and core diameter of about $208 \mathrm{~nm}$. The relative ratio of $\mathrm{TiO}_{1-x} \mathrm{~N}_{x}$ to $\mathrm{TiO}_{2}$ was determined on the basis of the TGA and EDX data for the sample nitrided at $700{ }^{\circ} \mathrm{C}$ for $24 \mathrm{~h}$.

Since the ratio of $\mathrm{TiO}_{1-x} \mathrm{~N}_{x}$ to $\mathrm{TiO}_{2}$ in the nitrided sample cannot be determined by the TGA data alone, the EDX elemental analysis was employed to help estimating the relative compositions in $\mathrm{TiO}_{2} @ \mathrm{TiO}_{1-x} \mathrm{~N}_{x}$. Although the EDX data are not completely reliable due to several factors such as surface, elements, and the specimen features, the technique provides reasonably reliable elemental compositions particularly for insoluble inorganic materials like $\mathrm{TiO}_{2} @ \mathrm{TiO}_{1-x} \mathrm{~N}_{x}$. Weight percentages of $\mathrm{Ti}$ and $\mathrm{N}$ of the samples nitrided for 10, 24, and $48 \mathrm{~h}$ were obtained directly from the EDX data and oxygen contents were calculated assuming that the samples are solely composed of $\mathrm{Ti}, \mathrm{N}$, and $\mathrm{O}$. Table $\mathrm{S} 2 \dagger$ gives weight percentages and atomic ratios for the three samples. As anticipated, the EDX data show that the nitrogen content increases as the annealing time increases.

Based on TGA and EDX data, the ratio of $\mathrm{TiO}_{1-x} \mathrm{~N}_{x}$ to $\mathrm{TiO}_{2}$ for the sample nitrided at $700{ }^{\circ} \mathrm{C}$ for $24 \mathrm{~h}$ is estimated to be 0.18 . For this calculation, we assumed that $\mathrm{TiO}_{2} @ \mathrm{TiO}_{1-x} \mathrm{~N}_{x}$ has a core-shell type structure because the nitridation occurs initially on the surface and gradually penetrates into the core. EDX data were taken to determine relative amounts of $\mathrm{N}$ and $\mathrm{O}$. As illustrated in the inset of Fig. 7, the shell thickness and the core diameter of the $\mathrm{TiO}_{2} @ \mathrm{TiO}_{1-x} \mathrm{~N}_{x}$ sample are $56 \mathrm{~nm}$ and 308 $\mathrm{nm}$, respectively.

Fig. 8 shows elemental mapping images and EDX line scan elemental profiles of the sample nitrided at $700{ }^{\circ} \mathrm{C}$ for $24 \mathrm{~h}$, clearly confirming the presence of $\mathrm{N}, \mathrm{O}$, and Ti. The Ti intensity is strong and the intensity profile along the line is nearly domeshaped. On the other hand, the intensities of $\mathrm{N}$ and $\mathrm{O}$ are relatively weak and did not noticeably change along the line due to their low scattering power. The elemental mapping images indicate that $\mathrm{N}, \mathrm{O}$, and Ti are evenly dispersed on the spherical surface and also imply that $\mathrm{TiO}_{1-x} \mathrm{~N}_{x}$ is mostly located on the outer portion of the shell. 
(a)

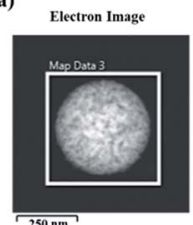

TIK series
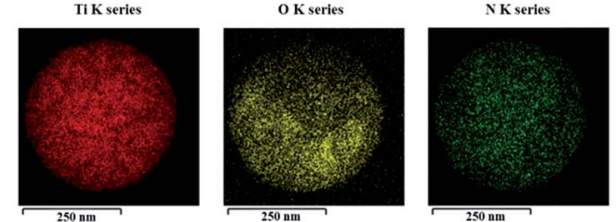

(b)
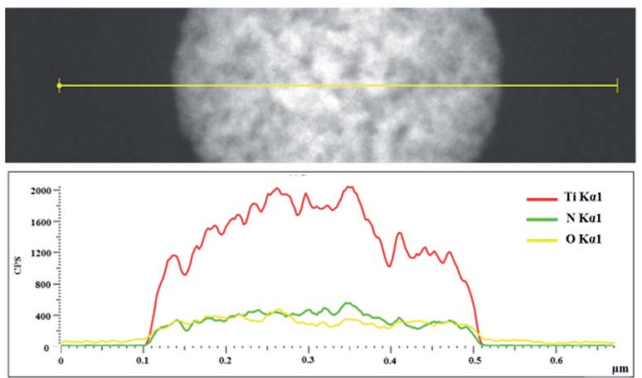

Fig. 8 (a) Elemental mapping images of $\mathrm{TiO}_{2}\left(\mathrm{aTiO}_{1-x} \mathrm{~N}_{x}\right.$ nitrided at $700{ }^{\circ} \mathrm{C}$ for $24 \mathrm{~h}$ by scanning TEM. (b) EDX line profiles of $\mathrm{N}, \mathrm{O}$, and Ti across the $\mathrm{TiO}_{2} \mathrm{QTiO}_{1-x} \mathrm{~N}_{x}$ interface.

As illustrated in Fig. 8, conventional TEM is very difficult to differentiate between core and shell components in $\mathrm{TiO}_{2} @$ $\mathrm{TiO}_{1-x} \mathrm{~N}_{x}$ mainly because the L-shell peak of Ti $(0.452 \mathrm{keV})$ and the K-shell peak of $\mathrm{N}(0.392 \mathrm{keV})$ were too close to distinguish their elemental intensities. We have thus investigated the structure and chemical composition of the bisected $\mathrm{TiO}_{2}$ @ $\mathrm{TiO}_{1-x} \mathrm{~N}_{x}$ microsphere with scanning transmission electron microscopy (STEM), electron energy loss spectroscopy (EELS), and energy-dispersive X-ray spectroscopy (EDS). A $\mathrm{TiO}_{2} @$ $\mathrm{TiO}_{1-x} \mathrm{~N}_{x}$ microsphere nitrided at $700{ }^{\circ} \mathrm{C}$ for $10 \mathrm{~h}$ was used and approximately bisected by a focused ion beam (FIB). Fig. 9 presents the bisected STEM image and the corresponding EDS elemental mapping images of $\mathrm{Ti}, \mathrm{O}$, and $\mathrm{N}$. The Ti and $\mathrm{O}$ signals are evenly dispersed in the core and shell parts of the bisected sphere whereas the $\mathrm{N}$ signals are located exclusively on the shell of the sphere, indicating that the $\mathrm{TiO}_{2} @ \mathrm{TiO}_{1-x} \mathrm{~N}_{x}$ microsphere has the core/shell structure. To further convince the compositions of the core and shell parts, we have investigated the STEMEDS analysis of the bisected sample. As given in Fig. S2, $\uparrow$ the Ti, $\mathrm{O}$, and $\mathrm{N}$ signals were observed in the shell part but only $\mathrm{Ti}$ and $\mathrm{O}$ signals were detected in the core. This clearly demonstrates
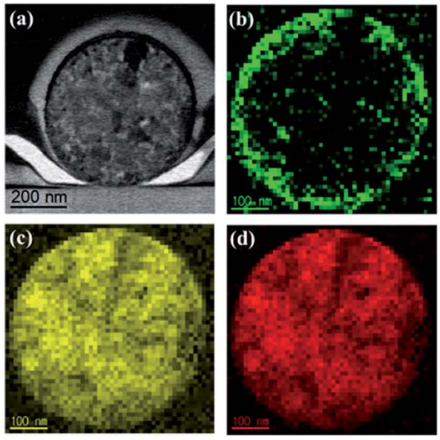

Fig. 9 (a) STEM images of a bisected $\mathrm{TiO}_{2}\left(\mathrm{aTiO}_{1-x} \mathrm{~N}_{x}\right.$ microsphere. The corresponding EELS mapping images of $\mathrm{N}$ ((b), green), $\mathrm{Ti}((\mathrm{c})$, yellow), and $O((d)$, red). (a)
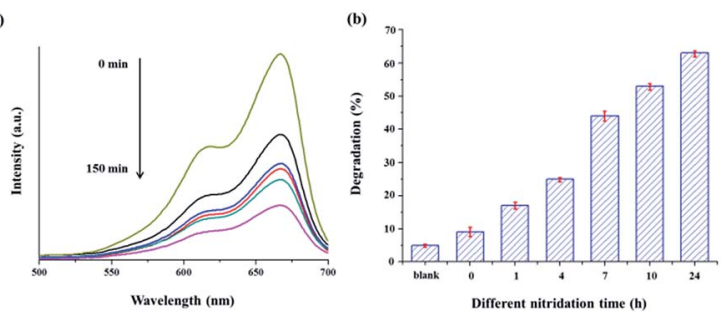

Fig. 10 (a) UV-visible spectra of the MB solution in the presence of $\mathrm{TiO}_{2} \mathrm{aTiO}_{1-x} \mathrm{~N}_{x}$ nitrided at $700{ }^{\circ} \mathrm{C}$ for $24 \mathrm{~h}$ under visible-light irradiation $(>420 \mathrm{~nm})$ as a function of time of exposure to light. (b) Percentage of photocatalytic degradation of $\mathrm{MB}$ over the $\mathrm{TiO}_{2} \mathrm{C}$ $\mathrm{TiO}_{1-x} \mathrm{~N}_{x}$ samples with different nitridation times.

that the $\mathrm{TiO}_{1-x} \mathrm{~N}_{x}$ phase is formed on the shell by the nitridation but the core $\mathrm{TiO}_{2}$ remains intact.

Diffuse reflectance UV-visible spectroscopy (DRUVS) was employed to determine whether the nitrided sample absorbs light effectively in the visible light region. The DRUVS spectrum of $\mathrm{TiO}_{2} @ \mathrm{TiO}_{1-x} \mathrm{~N}_{x}$ nitrided at $700{ }^{\circ} \mathrm{C}$ for $24 \mathrm{~h}$ clearly shows that the sample absorbs much more light in the visible regions in comparison with that of $\mathrm{TiO}_{2}$ (Fig. S3 $\dagger$ ). Thus the photocatalytic activity of $\mathrm{TiO}_{2} @ \mathrm{TiO}_{1-x} \mathrm{~N}_{x}$ nitrided at $700{ }^{\circ} \mathrm{C}$ for $24 \mathrm{~h}$ was evaluated by measuring the degradation rate of methylene blue (MB) under visible light as a function of time. The absorbance of $\mathrm{MB}$ at $664 \mathrm{~nm}$, which is the strongest peak of $\mathrm{MB}$, was used to determine the concentration change of the MB solution. ${ }^{33}$

As shown in Fig. 10(a), the strong absorption peak is continuously weakened with increasing irradiation time. This clearly indicates that the $\mathrm{TiO}_{2} @ \mathrm{TiO}_{1-x} \mathrm{~N}_{x}$ catalyst efficiently decomposes MB under visible light. Similar efficient activities were also observed in all the samples nitrided at $700{ }^{\circ} \mathrm{C}$. Among them, the sample nitrided for $24 \mathrm{~h}$ has the highest performance on the MB decomposition, which is given in Fig. 10(b). Due to the large band gap energy $\left(E_{\mathrm{g}}=3.2 \mathrm{eV}\right)$ of $\mathrm{TiO}_{2}$, the core $\mathrm{TiO}_{2}$ is inactive in decomposition of $\mathrm{MB}$ under visible light. Therefore, it is evident that the $\mathrm{TiO}_{1-x} \mathrm{~N}_{x}$ phase in the shell is the only

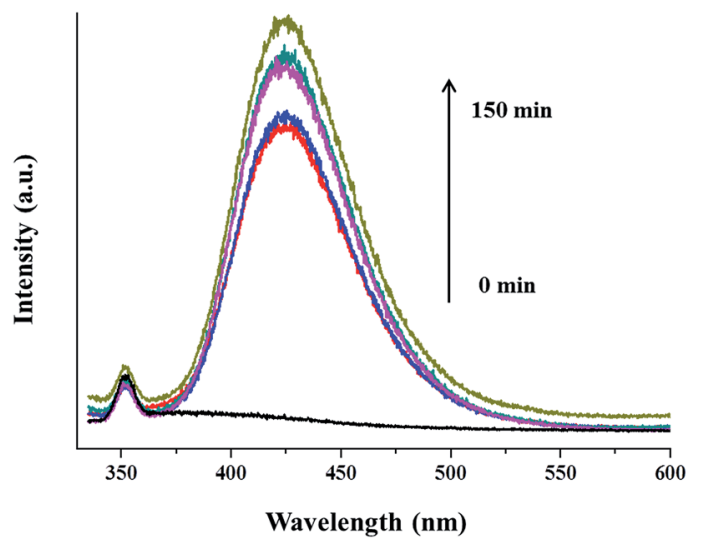

Fig. 11 Time-dependent fluorescence spectra obtained from the illumination of a $\mathrm{NaOH}$ solution of terephthalic acid in the presence of $\mathrm{TiO}_{2}\left(\mathrm{QTiO}_{1-x} \mathrm{~N}_{x}\right.$ nitrided at $700{ }^{\circ} \mathrm{C}$ for $24 \mathrm{~h}$. Each spectrum was recorded every 30 min of illumination. 


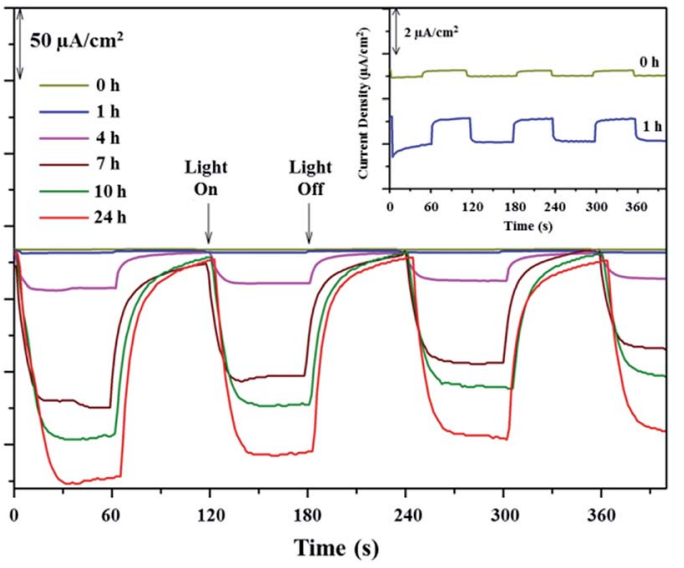

Fig. 12 Photocurrent response of the $\mathrm{TiO}_{2}\left(\mathrm{aTiO}_{1-x} \mathrm{~N}_{x}\right.$ samples with different nitridation times under an applied potential of $0.8 \mathrm{~V}$ ( $v s$. Ag/ $\mathrm{AgCl})$ and a periodic irradiation of visible light.

active component in the visible range of irradiation and can be considered as a visible-light photocatalyst. This result is consistent with that of the DRUVS data.

To elucidate whether hydroxyl radicals ( $\left.{ }^{\circ} \mathrm{OH}\right)$ produced from the illumination of $\mathrm{TiO}_{2} @ \mathrm{TiO}_{1-x} \mathrm{~N}_{x}$ lead to the degradation of $\mathrm{MB}$, we have employed the fluorescence technique that is usually used to estimate the formation of hydroxyl radicals on the surface of the photocatalyst. ${ }^{34-36}$ Fig. 11 shows the fluorescence spectral change of the terephthalic acid in the presence of $\mathrm{TiO}_{2} @ \mathrm{TiO}_{1-x} \mathrm{~N}_{x}$ nitrided at $700{ }^{\circ} \mathrm{C}$ for $24 \mathrm{~h}$ with increasing irradiation time. A new peak at about $425 \mathrm{~nm}$, due to the hydroxylation product (2-hydroxyterephthalic acid), is distinctively displayed in the illuminated spectrum. The fluorescence intensity is gradually increased with increasing irradiation time. Based on these results, it is evident that the hydroxyl radicals generated from the $\mathrm{TiO}_{2} @ \mathrm{TiO}_{1-x} \mathrm{~N}_{x}$ catalyst plays a significant role in the decomposition of MB.

In addition to the chemical degradation of $\mathrm{MB}$ by the hydroxyl radicals, we also evaluated the capability of photocurrent generation of the nitrided samples under visible light. The photocurrent density was clearly observed, which was very reproducible in the repeated on/off cycles of excitation.

As illustrated in Fig. 11, the photocurrent of the nitrided samples is enhanced when the nitridation time increased. The sample nitrided for $24 \mathrm{~h}$ has the largest value of photocurrent density $\left(\sim 170 \mu \mathrm{A} \mathrm{cm}{ }^{-2}\right)$, which is comparable with that of carbon nitride $\left(\mathrm{C}_{3} \mathrm{~N}_{4}\right)^{37,38}$ This clearly demonstrates that the $\mathrm{TiO}_{2} @ \mathrm{TiO}_{1-x} \mathrm{~N}_{x}$ catalyst is able to generate photocurrents effectively under visible light while $\mathrm{TiO}_{2}$ does not produce photocurrents under the same conditions (Fig. 12).

\section{Conclusions}

The present study demonstrated the successful synthesis of new composite photocatalysts $\left(\mathrm{TiO}_{2} @ \mathrm{TiO}_{1-x} \mathrm{~N}_{x}\right)$ with enhanced visible light activity, which was accomplished by a controlled nitridation of $\mathrm{TiO}_{2}$ microspheres. The nitrided products maintain a spherical shape and have a unique core/shell structure.
The core and shell parts are mainly composed of amorphous $\mathrm{TiO}_{2}$ and crystalline $\mathrm{TiO}_{1-x} \mathrm{~N}_{x}$ phases, respectively. They exhibited high photocatalytic and photoelectrochemical activities under visible light irradiation. Our structural and spectroscopic results confirm that the origin of their activity is due primarily to the $\mathrm{TiO}_{1-x} \mathrm{~N}_{x}$ phase. Specifically, the nitrogen dopant in $\mathrm{TiO}_{1-x} \mathrm{~N}_{x}$ appears to be responsible for photocatalytic activity under visible-light similar to the well-documented $\mathrm{N}$ doped $\mathrm{TiO}_{2}$ phase $\left(\mathrm{TiO}_{2-x} \mathrm{~N}_{x}\right)$. Our studies on the $\mathrm{TiO}_{1-x} \mathrm{~N}_{x}$ phase having a simple rock-salt structure promise a wide range of visible-light applications in both photocatalytic and photoelectrochemical systems.

\section{Acknowledgements}

We express gratitude to the editorial staff at Sogang University for the careful English revision of this manuscript.

\section{Notes and references}

1 A. Fujishima and K. Honda, Nature, 1972, 238, 37-38.

2 X. B. Chen and S. S. Mao, Chem. Rev., 2007, 107, 2891-2959.

3 J. Huo, Y. Hu, H. Jiang and C. Li, Nanoscale, 2014, 6, 90789084.

4 C. Dette, M. A. Pérez-Osorio, C. S. Kley, P. Punke, C. E. Patrick, P. Jacobson, F. Giustino, S. J. Jung and K. Kern, Nano Lett., 2014, 14, 6533-6538.

5 J. Zhang, P. Zhou, J. Liu and J. Yu, Phys. Chem. Chem. Phys., 2014, 16, 20382-20386.

6 X. Chen, L. Liu, P. Y. Yu and S. S. Mao, Science, 2011, 331, $746-750$.

7 J. C. Yu, J. Yu, W. Ho, Z. Jiang and L. Zhang, Chem. Mater., 2002, 14, 3808-3816.

8 S. Hoang, S. P. Berglund, N. T. Hahn, A. J. Bard and C. B. Mullins, J. Am. Chem. Soc., 2012, 134, 3659-3662.

9 J. Zhang, Y. Wu, M. Xing, S. A. K. Leghari and S. Sajjad, Energy Environ. Sci., 2010, 3, 715-726.

10 R. Asahi, T. Morikawa, T. Ohwaki, K. Aoki and Y. Taga, Science, 2001, 293, 269-271.

11 M. Zhou and J. Yu, J. Hazard. Mater., 2008, 152, 1229-1236.

12 A. Naldoni, F. Fabbri, M. Altomare, M. Marelli, R. Psaro, E. Selli, G. Salviati and V. D. Santo, Phys. Chem. Chem. Phys., 2015, 17, 4864-4869.

13 A. Naldoni, M. Allieta, S. Santangelo, M. Marelli, F. Fabbri, S. Cappelli, C. L. Bianchi, R. Psaro and V. D. Santo, J. Am. Chem. Soc., 2012, 134, 7600-7603.

14 J. Wang, D. N. Tafen, J. P. Lewis, Z. Hong, A. Manivannan, M. Zhi, M. Li and N. Wu, J. Am. Chem. Soc., 2009, 131, 12290-12297.

15 J. Graciani, S. Hamad and J. F. Sanz, Phys. Rev. B: Condens. Matter Mater. Phys., 2009, 80, 184112/1-184112/10.

16 S. G. Seo, C. Park, H. Kim, W. H. Nam, M. Jeong, Y. Choi, Y. S. Lim, W. Seo, S. Kim, J. Y. Lee and Y. S. Cho, J. Mater. Chem. A, 2013, 1, 3639-3644.

17 P. Simon, B. Pignon, B. Miao, S. C. Leconte, Y. Leconte, S. Marguet, P. Jegou, B. B-Fabre, C. Reynaud and N. HBoime, Chem. Mater., 2010, 22, 3704-3711. 
18 V. Ern and A. C. Switendick, Phys. Rev., 1965, 137, A1927A1936.

19 P. Zheng, J. Zhao, J. Zheng, G. Ma and Z. Zhu, J. Mater. Chem., 2012, 22, 12116-12120.

20 C. Gong, C. Yan, J. Zhang, X. Cheng, H. Pan, C. Zhang, L. Yu and Z. Zhang, J. Mater. Chem., 2011, 21, 15273-15278.

21 E. P. Quijorna, V. T. Costa, F. A. Rueda, P. H. Fernández, A. Climent, F. Rossi and M. M. Silván, J. Phys. D: Appl. Phys., 2011, 44, 235501/1-235501/8.

22 X. Chen, L. Liu, P. Y. Yu and S. S. Mao, Science, 2011, 331, 746-750.

23 O. Frank, M. Zukalova, B. Laskova, J. Kürti, J. Koltai and L. Kavan, Phys. Chem. Chem. Phys., 2012, 14, 14567-14572.

24 A. T-Zajac, M. Radecka, K. Zakrzewska, A. Brudnik, E. Kusior, S. Bourgeois, M. C. Lucas and L. Imhoff, J. Power Sources, 2009, 194, 93-103.

25 W. Spengler, R. Kaiser and H. Bilz, Solid State Commun., 1975, 17, 19-22.

26 W. Spengler, R. Kaiser, A. N. Christensen and G. M. Vogt, Phys. Rev. B: Condens. Matter Mater. Phys., 1978, 17, 10951101.

27 H. G. Yang, C. H. Sun, S. Z. Qiao, J. Zou, G. Liu, S. C. Smith, H. M. Cheng and G. Q. Lu, Nature, 2008, 453, 638-642.
28 F. Peng, L. Cai, L. Huang, H. Yu and H. Wang, J. Phys. Chem. Solids, 2008, 69, 1657-1664.

29 W. Göpel, G. Rocker and R. Feierabend, Phys. Rev. B: Condens. Matter Mater. Phys., 1983, 28, 3427-3438.

30 X. Song, D. Gopireddy and C. G. Takoudis, Thin Solid Films, 2008, 516, 6330-6335.

31 M. Wolff, J. W. Schultze and H. H. Strehblow, Surf. Interface Anal., 1991, 17, 726-736.

32 I. Takahashi, D. J. Payne, R. G. Palgrave and R. G. Egdell, Chem. Phys. Lett., 2008, 454, 314-317.

33 W. Cai, G. Duan and Y. Li, Hierarchical Micro/Nanostructured Materials: Fabrication, Properties and Applications, CRC Press, Taylor and Francis Group, 2014.

34 J. Zhang and Y. Nosaka, J. Phys. Chem. C, 2013, 117, 13831391.

35 L. Sun, Y. Qin, Q. Cao, B. Hu, Z. Huang, L. Ye and X. Tang, Chem. Commun., 2011, 47, 12628-12630.

36 T. P. Gujar, C. Anand, V. R. Shinde, J. Ye, K. Ariga and A. Vinu, J. Nanosci. Nanotechnol., 2010, 10, 8124-8129.

37 J. Fang, H. Fan, M. Li and C. Long, J. Mater. Chem. A, 2015, 3, 13819-13826.

38 J. Liu, H. Wang, Z. P. Chen, H. Moehwald, S. Fiechter, R. Krol, L. Wen, L. Jiang and M. Antonietti, Adv. Mater., 2015, 27, 712-718. 